\title{
Gestational age and the $C$ reactive protein response
}

\author{
M A Turner, S Power, A J B Emmerson
}

Arch Dis Child Fetal Neonatal Ed 2004;89:F272-F273. doi: 10.1136/adc.2002.011288

$C$ reactive protein (CRP) concentrations are used routinely in the investigation and monitoring of neonatal sepsis. In this study, CRP responses were examined in the first week after birth. Among infants showing a clinically relevant CRP response, CRP concentrations $>60 \mathrm{mg} / \mathrm{l}$ were more likely with increasing gestational age.

$\mathrm{P}$ rompt diagnosis of neonatal sepsis is of paramount importance, yet can be difficult because of subtle and non-specific clinical features. Assay of serum $\mathrm{C}$ reactive protein (CRP) has been shown to be useful in the diagnosis and management of neonatal sepsis, with a higher likelihood ratio for the prediction of sepsis than many other tests. ${ }^{1}$ Although some small studies have examined the CRP response in term and preterm infants, ${ }^{2-6}$ the relation between gestational age and CRP response has not been studied in detail. In the light of our clinical experience, we hypothesised that the magnitude of a clinically relevant CRP response $(\geqslant 10 \mathrm{mg} / \mathrm{l})$ in the first week after birth increases with increasing gestational age.

\section{METHODS}

Our unit database includes CRP concentrations obtained in the first seven days after delivery for 3574 infants born between 24 and 41 weeks of gestation; a total of 10703 values obtained between 1993 and 2002 were available for analysis. CRP was measured using an Hitachi modular system. The laboratory defined a clinically relevant CRP response as a concentration of $\geqslant 10 \mathrm{mg} / \mathrm{l}$. We defined a pronounced CRP response as a concentration of $\geqslant 60 \mathrm{mg} / \mathrm{l}$.

\section{RESULTS}

A clinically relevant increase in CRP in the first seven days after birth was noted in 193/489 (39\%) of infants born at 2427 weeks gestation, $217 / 727(30 \%)$ of infants born at 28 31 weeks, 209/1090 (19\%) at 32-35 weeks, 203/816 (25\%) at $36-39$ weeks, and $190 / 490(39 \%)$ at 40 or 41 weeks. The median day of maximum CRP was two for all gestational ages. Table 1 shows the distribution of CRP responses among those infants who showed a clinically relevant CRP response.

Of those infants with a clinically relevant rise in CRP, a $\mathrm{CRP} \geqslant 60 \mathrm{mg} / \mathrm{l}$ was noted in 16/193 (8.3\%) of infants born at 24-27 weeks gestation, 23/217 (11\%) of infants born at 2831 weeks, $29 / 209(14 \%)$ at 32-35 weeks, 50/203 (25\%) at 3639 weeks, and $48 / 190(25 \%)$ at 40 or 41 weeks ( $p<0.001, \chi^{2}$ for trend; fig 1). This pattern of results was also found when we examined infants with the maximum CRP (a) within 72 hours of delivery or $(b)$ subsequent to the 72 hours after delivery (data not shown) or grouped the infants by birth weight (data not shown).

\section{DISCUSSION}

Among infants with a clinically relevant rise in CRP, infants born at extreme prematurity were less likely to show an appreciable increase in CRP than infants born later in gestation. Furthermore, the likelihood of a CRP response being pronounced increases steadily with gestational age: there was not a clear gestational age when CRP production increased.

There are several explanations for these observations, although this retrospective pilot study could not examine all the appropriate variables. Factors triggering a proinflammatory response may be present in different proportions at different gestational ages-for example, the organisms responsible for an infection may be different at different gestational ages. The clinical management of the infants may differ-for example, infants born earlier in gestation are more likely to receive antibiotics in the hours immediately after birth than infants born at term. We observed that the timing of maximum CRP response did not alter the relation between gestational age and likelihood of a pronounced CRP response. This suggests that any effects of differences in clinical management that account for the effect of gestational age on CRP relate to illnesses manifesting both in the first 72 hours after delivery and thereafter.

Table 1 Magnitude of clinically relevant $C$ reactive protein (CRP) responses in each gestational age band

\begin{tabular}{lllll}
\hline \multicolumn{5}{c}{} \\
& \multicolumn{3}{l}{$\begin{array}{l}\text { Percentage of each gestational age group in } \\
\text { each CRP band }\end{array}$} \\
\cline { 2 - 5 } & $10-29$ & $30-59$ & $60-99$ & 100 or more \\
\hline $\begin{array}{l}\text { Gestational age } \\
\text { (weeks) } \\
24-27\end{array}$ & 69 & 22 & 6 & 2 \\
$28-31$ & 63 & 27 & 8 & 2 \\
$32-35$ & 66 & 20 & 10 & 4 \\
$36-39$ & 50 & 25 & 15 & 10 \\
$40-41$ & 51 & 24 & 17 & 8 \\
\hline CRP bands are measured in mg/l.
\end{tabular}

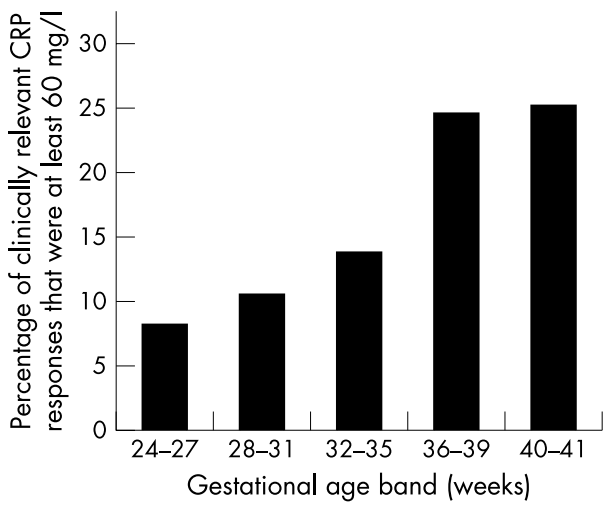

Figure 1 Proportion of infants with a pronounced $C$ reactive protein (CRP) response ( $\geqslant 60 \mathrm{mg} / \mathrm{l}$ ) in each gestational age band. 
Maturational changes in the immune system are the most likely explanation for the increasing likelihood with increasing gestational age of a pronounced CRP response. The nature of these maturational changes will require further study. There does not appear to be a single gestational age band at which the CRP response becomes mature. This would argue against a single developmental "switch" in the magnitude of CRP response. The effects of gestational age are likely to be modulated by factors such as those listed above.

We note that fewer infants born between 32 and 35 weeks gestation showed a clinically relevant rise in CRP. This probably reflects the greater incidence of obstetrician initiated delivery for conditions such as intrauterine growth restriction in this group of infants. This reinforces our focus on infants with a clinically relevant CRP concentration rather than all infants with available CRP concentrations. Previous studies on CRP response in preterm infants have typically included less than 40 infants with a clinically relevant response and did not stratify by gestational age. ${ }^{2-6}$ Thus our study of 1012 infants with a CRP response is significantly larger than those presented previously and provides novel information about the CRP response.

We have shown how gestational age is related to one manifestation of a proinflammatory response. However, gestational age is probably one of many influences on the magnitude of the CRP response. We speculate that prospective investigation of the influences on CRP production could define patterns of expected and unexpected response to clinical events, which would help the clinician individualise the care offered to high risk infants.

\section{ACKNOWLEDGEMENTS}

We are grateful to Dr R Pumphrey for help with data collection.

\section{Authors' affiliations}

M A Turner, S Power, A J B Emmerson, St Mary's Hospital, Whitworth Park, Manchester, UK

Correspondence to: Dr Turner, Neonatal Medical Unit, St Mary's Hospital, Hathersage Road, Manchester M13 OJH, UK;

mark.turner@man.ac.uk

Accepted 10 March 2003

\section{REFERENCES}

1 Fowlie PW, Schmidt B. Diagnostic tests for bacterial infection from birth to 90 days: a systematic review. Arch Dis Child Fetal Neonatal Ed 1998;78:F92-8.

2 Speer C, Bruns A, Gahr M. Sequential determination of CRP, $\alpha_{1}$-antitrypsin and haptoglobin in neonatal septicaemia. Acta Paediatr Scand 1983;72:679-83

3 Wasunna A, Whitelaw A, Gallimore R, et al. C-reactive protein and bacterial infection in preterm infants. Eur J Pediatr 1990;149:424-7.

4 Seibert K, Yu VY, Doery JC, et al. The value of C-reactive protein measurement in the diagnosis of neonatal infection. J Paediatr Child Health 1990;26:267-70.

5 Doellner H, Arntzen KJ, Haereid PE, et al. Interleukin-6 concentration in neonates evaluated for sepsis. J Pediatr 1998;132:295-9.

6 Benitz WE, Han MY, Madan A, et al. Serial serum C-reactive protein levels in the diagnosis of neonatal infection. Pediatrics 1998;102:e41. 